\title{
$x$-AMINOCYCLIC AND BICYCLIC ALKANE CARBOXYLIC ACIDS: DIFFERENTIAL EFFECTS ON SELECTED AMINO ACIDS OF RAT BRAIN CORTEX ${ }^{1}$
}

\author{
R. ZAND, O. Z. SellingFr, ${ }^{*}$ R. WATER and R. HARR IS \\ Biophysics Research Division, Institute of Science and Tcehnology. Department of \\ Biological Chemistry, University of Michigan, Ann Arbor. Ml 48105. U.S.A. and \\ * Laboratory of Neurochemistry, Mental Health Research Institute. University of Michigan,
} Ann Arbor. MI 48104. U.S.A.

(Receited 13 February 1974. Accepted 22 May 1974)

\begin{abstract}
The intraperitoneal administration of 1-aminocyclopentane carboxylic acid, 1-aminocyclohexane carboxylic acid, 1-aminocycloheptane carboxylic acid, 1-aminocyclooctane carboxylic acid, exo-2aminobicyclo(2,2,1)heptane-2-carboxylic acid. enio-2-aminobicyclo(2,2.1)heptane-2-carboxylic acid. 2aminobicyclo(2,2.2)octane-2-carboxylic acid and 2-aminobicyclo(3,2.1)octane-2-carboxylic acid to 18-dayold male rats selectively perturbed the levels of neutral amino acids in the cerebral cortex. While the effect of the above compounds was rather diversified and usually resulted in a reduction of amino acid levels. marked clevations of the levels of valine and isoleucine were also noted. 1-Aminocycloheptane and -cyclooctane carboxylic acids were particularly noteworthy, in that they elicited a marked reduction of the levels of cortical phenylalanine.
\end{abstract}

RESF.ARCH in our and other laboratories has shown that several non-metabolizable analogues of natural amino acids possess unique biochemical properties in that they affect amino acid transport as well as endogenous brain amino acid levels (CHRISTENSEN et al.. 1969; Zand et al.. 1972; Sfllingfre et al.. 1972; Schain \& WATANABE. 1972). It was of interest to extend these studies to see if some newly synthesized cyclic and bicyclic amino acids perturb the amino acid pool of brain tissue selectively. Previous reports in the literature have. for the most part, measured the effects of the administration of large doses of natural amino acids on the brain amino acid pool, focusing on the identifcation of specific regulatory mechanisms for their transport across the blood-brain barrier. Thus Lowime \& LARAMt: (1969) have shown that the branched chain amino acids decrease in the rat brain as a result of the administration of large doses of phenylalanine, while the findings of Richter \& WAINER (1971) provide evidence for the existence of separate systems for the transport of neutral and basic amino acids across the blood-brain barrier. For a review of the earlier literature in this field see Neam:

'This work was supported by grants from the National Science Foundation (GB 21435, R.Z) and the Uniled States Public Health Service (NS 06294. O.Z.S.).
(1968). Regional differences in amino acid distribution and movement have been examined by BATTISTIN \& LAJTHA (1970), while more recently Piccol. et al. (1971) noted changes in the pattern of inhibition of the transport of glycine, alanine and leucine into rat brain slices by 2-aminobicyclo(2.21) heptane-2-carboxylic acid $(\mathrm{BCH})$. The extent of the inhibition was highest for the uptake of leucine and was age-dependent confirming a previous report by one of us in which similar effects of BCH on amino acid transport in cirro were observed in rat liver. pigeon erythrocytes and ascites tumor cells (CHRISTFNSIN ot al.. 1969).

The present study reports the results of experiments in which the effects of the administration in rito of both geometric isomers of $\mathrm{BCH}$ and of four monocyclic and two new bicyclic amino acids were investigated. In particular. the effect of these compounds on the levels of the neutral and aromatic amino acids of rat cerebral cortex was examined. The results show that the levels of some amino acids were selectively and specifically perturbed while those of others remained unchanged. A preliminary report of some of the results has appeared (ZAND et al., 1972).

\section{METHODS}

The experimental design utilized in this study consisted of the intraperitoneal administration of $4.7 \mathrm{mmol} \mathrm{kg}$ of the 
Selie and bicyclic amino acids, a dose independently determined to be free of overt toxic effects. The amino acid pool was prepared (StLLINGt:R et al., 1972) from the cerebral cortex of the injected rats 1 and $3 \mathrm{~h}$ after the administration of the two $\mathrm{BCH}$ isomers and $\mathrm{I} \mathrm{h}$ after the administration of the other synthetic amino acids. the $3 \mathrm{~h}$ analyses not being performed as maximum alterations from control levels occurred already at I h (unpublished observations).

Amino acid analyses were performed on a Spinco Model $120 C$ amino acid analyser using the standard two column method

\section{Sinthetic}

The cyclic amino acids were prepared via their respective hydantoins, combining the procedure of BUCHERER \& LIEB (19.34) and the more recent modifications of CONNORS \& Ross (1960).

\section{5'-Cyclopentane spirohydantoin}

Cyclopentanone $84.1 \mathrm{~g}(1.0 \mathrm{~mol})$ in $350 \mathrm{ml}$ of ethanol was mixed with a solution of $173 \mathrm{~g}(1.8 \mathrm{~mol})$ of ammonium carbonate in $500 \mathrm{ml}$ of distilled water. The mixture was warmed to $50^{\circ} \mathrm{C}$ in a water bath and a solution of potassium cyanide $65 \mathrm{~g}(1.0 \mathrm{~mol})$ in $150 \mathrm{ml}$ of distilled water was added. The flask was stoppered and placed in a water bath at $60^{\circ} \mathrm{C}$ for $6 \mathrm{~h}$. The reaction mixture was then distilled until the volume had been reduced by one-half and then allowed to cool. The crystalline precipitate was collected and the mother liquor carefully acidified to $\mathrm{pH} 2$ with concentrated sulphuric acid whereupon a second crop of crystals was obtained. Recrystallization of the product from water and Norite gave $145 \mathrm{~g}$ of hydantoin m.p. $205-207^{\circ} \mathrm{C}$. Reported by HENZE \& SPEER (1942): 204-205-C.

\section{1- Aminoc clopentane carboxylic acid (Compound 1)}

The 5.5'-cyclopentane spirohydantoin $130 \mathrm{~g}(0.84 \mathrm{~mol})$ and barium hydroxide octahydrate $453 \mathrm{~g}(1.44 \mathrm{~mol})$ in $2 \mathrm{l}$. of distilled water were heated in an autoclave at $120^{\circ} \mathrm{C}$ for $12 \mathrm{~h}$. After cooling. the precipitated barium carbonate was removed by filtration and the mother liquor treated with ammonium carbonate and dry ice until no additional precipitation occurred. Concentration of the filtered solution in a stainless steel beaker on a hot plate to one-fourth the original volume and cooling to room temperature overnight yielded the amino acid. Recrystallization from ethanol water gave $85 \mathrm{~g}$ of product which after drying at $110^{\circ} \mathrm{C}$ had a m.p. of $315-317^{\circ} \mathrm{C}$. Reported by ZELINSKY \& STADNIKOFF (1911): $320^{\circ} \mathrm{C}$.

\section{1-Aminocyclohexane carboxylic acid (Compound 2)}

The 5.5'-cyclohexane spirohydantoin prepared as above m.p. 217-220 C, reported by CONNORs \& Ross (1960) m.p. $221-225^{\circ} \mathrm{C}$. was hydrolysed by barium hydroxide at $120^{\circ}$ giving 1-aminocyclohexane carboxylic acid which after recrystallization from water had a m.p. of $334-337^{\circ} \mathrm{C} \mathrm{dec}$. or $335^{\circ} \mathrm{C}$ in a sealed tube. Reported by ZELINSKY \& STADNIKOFF (1906): $334-335^{\circ} \mathrm{C}$.
1-Aminorycloheplane carboxylic acid (Compound 3)

The amino acid prepared from the hydantoin. m.p. 214$216 \mathrm{C}$ by hydrolysis with barium hydroxide yielded the amino acid having a m.p. of $315-317 \mathrm{C} \mathrm{dec}$. after recrystallization from water. Reported by Convors \& Ross $(1960)$ : $320 \mathrm{C}$.

\section{1-Aminocyclooctane carboxylic acid (Compound 4)}

The 5,5-cyclooctane spirohydantoin m.p. 240-242 C upon hydrolysis with barium hydroxide yielded the amino acid. m.p. 310 312 C dec. Reported by Duonch e'l al. (1964): $310-316 \mathrm{C}$ dec.

\section{2-Aminobicyclo(2,2,1)heptane-2-carboxylic acid isomer $h$} $(B C H-b)(C$ ompound 5)

This amino acid was prepared by a modification of our previously reported method (CHRISTENStN et al. 1969). A solution of $220 \mathrm{~g}$ (2.0 mol) of norbornanone was dissolved in 1 litre of $95^{\circ}{ }_{0}$ ethanol and cooled to $5 \mathrm{C}$. To this solution was auded $130 \mathrm{~g}(2.0 \mathrm{~mol})$ of $\mathrm{KCN}$ in $500 \mathrm{ml}$ of distilled water at $4 \mathrm{C}$ and $250 \mathrm{~g}(2.6 \mathrm{~mol})$ of $\left(\mathrm{NH}_{4}\right)_{2} \mathrm{CO}_{3}$ in $500 \mathrm{ml}$ of distilled water at $4-\mathrm{C}$. The mixture was allowed to stand at $4 \mathrm{C}$ for 30 days and then filtered to obtain the precipitated hydantoin. After recrystallization $150 \mathrm{~g}$ of spirohydantoin was obtained. The hydantoin was hydrolysed with barium hydroxide at $120^{\circ} \mathrm{C}$ for $48 \mathrm{~h}$ and the amino acid isolated and purified as described previously (CHRISTENSEN et al., 1969). Amino acid analysis indicated that the product was better than 98 per cent pure $b$ isomer.

\section{2-Aminobicyclo(2,2,1)heptane-2-carboxylic acid isomer a (BCH-a) (Compound 6)}

To a solution of $110 \mathrm{~g}(1.0 \mathrm{~mol})$ of norbornanone in $250 \mathrm{ml}$ of methanol in a 1 litre round bottom flask was added $55 \mathrm{~g}(1.0 \mathrm{~mol})$ of $\mathrm{NH}_{4} \mathrm{Cl}$ and $65.2 \mathrm{~g}(1.0 \mathrm{~mol})$ of $\mathrm{KCN}$ in $250 \mathrm{ml}$ of distilled water. The flask was stoppered and placed in a water bath at $80-85^{\circ} \mathrm{C}$ for $8 \mathrm{~h}$. After cooling to room temperature the contents were transferred to a $3-1$. beaker in a hood and concentrated $\mathrm{HCl}$ was added until the $\mathrm{pH}$ of 1.0 was reached. The solution was transferred to a $2-1$. round bottom flask and concentrated on a rotary evaporator until nearly dry. The collected amino nitrile hydrochloride was recrystallized rapidly from boiling $\mathrm{HCl}$ containing some Norite. Three recrystallizations yiclded a whitc powder of m.p. $198-200 \mathrm{C}$ dec.

The recrystallized amino nitrile hydrochloride was dissolved in 1 litre of $6 \mathrm{~N} \mathrm{HCl}$ and autoclaved at $120 \mathrm{C}$ for $24 \mathrm{~h}$. The solution was filtered through a sintered glass funnel while still hot, the filtrate distilled until the original volume was reduced by 70 per cent, and the remaining liquid then removed on a rotary evaporator. The residual powder was dried at $110^{\circ} \mathrm{C}$ overnight and triturated repeatedly (at least 6 times $\}$ in $/ / 1$ ( $v / v)$ methanol ether. The residue was redissolved in water. taken to dryness and the trituration repeated. The combined mothanol-ether extracts were taken to dryness and the residue dissolved in $500 \mathrm{ml}$ of boiling water. filtered and cooled rapidly in an ice bath. Upon 
adjusting the $\mathrm{pH}$ to 5.5 the amino acid precipitated. Analysis of the product on the amino acid analyser indicated it to be at least 99 per cent isomer a, m.p.: $321-323 \mathrm{C}$ dec.

2-Aminohic yclo(2,2,2)octane-2-curboxylic acid (Compound 7)

The desired ketone for the preparation of the hydantoin was prepared from bicyclo(2,2,2)octane-2-ene by the procedure of KLFINFELTTR \& SCHLLYLR (1962).

The hydantoin was prepared by treating $14.5 \mathrm{~g}$ (0.117 mol) of ketone with $7.6 \mathrm{~g}(0.117 \mathrm{~mol})$ of $\mathrm{KCN}$ and 22.4 (1).234 mol) of $\left(\mathrm{NH}_{4}\right)_{2} \mathrm{CO}_{3}$ in $250 \mathrm{ml}$ of $\mathrm{l} / 1$ (v/v) ethanolwater at $60 \mathrm{C}$ for $6 \mathrm{~h}$ and then allowing the mixture to stand at room temperature overnight. Yield: $19 \cdot 53 \mathrm{~g}$. m.p.: $274 \mathrm{C}$.

The hydantoin was treated with barium hydroxide at 120 $\mathrm{C}$ in an autoclave for $24 \mathrm{~h}$ and the producl isolated as in previous preparations. Yield: $5.72 \mathrm{~g}$. m.p.: $305 \mathrm{C} \mathrm{dec}$

2-Aminobicyclo(3,2.1)octane-2-carboxylic acid (Compound 8)

The desired hydantoin was prepared from the ketone by the method described for the preparation of the bicyclor2.2.2)octane homologue. Yield: 72 per cent. m.p.: 258 $260 \mathrm{C}$.

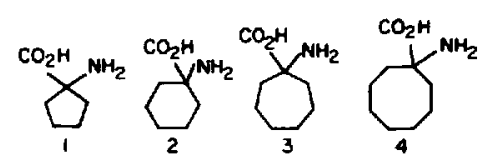

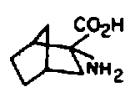

5

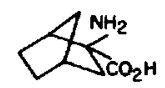

6

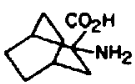

7 e

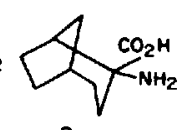

Fig. 1. Structural formulas and numerical designation of the cyclic and bicyclic amino acids.

(1) 1-Aminocyclopentanecarboxylic acid: (2) 1-aminocyclohexanecarboxylic acid: (3) 1-aminocycloheptanecarboxylic acid; (4) 1-aminocyclooctanecarboxylic acid; (5) endo-2aminobicyclo(2,2,1)heptane-2-carboxylic acid; (6) exo-2aminobicyclo $(2,2,1$ )heptane-2-carboxylic acid; (7) 2-aminobicyclo(2,2,2)octane-2-carboxylic acid; (8) 2-aminobicyclo(3,2,1)octane-2-carboxylic acid.

TABLE 1. THE EFFECT OF THF endo- AND eXo-ISOMERS OF 2-AMINOBICYCLO(2.21)HEPTANE-2-CARBOXYLIC ACID ON THE NEU TRAL. FREE AMINO ACID POOL OF 18-DAY-OLD RAT CEREBRAL CORTEX

\begin{tabular}{|c|c|c|c|c|c|}
\hline \multirow{2}{*}{$\begin{array}{l}\text { Cortical } \\
\text { amino } \\
\text { acid }\end{array}$} & \multirow[b]{2}{*}{ Control } & \multicolumn{2}{|c|}{ Compound 5} & \multicolumn{2}{|c|}{ Compound 6} \\
\hline & & I h & $3 \mathrm{~h}$ & $1 \mathrm{~h}$ & $3 \mathrm{~h}$ \\
\hline Phenylalanine & $\begin{array}{c}0.032 \pm \frac{ \pm}{(7)} \\
0.045 \pm \frac{ \pm 002}{(8)}\end{array}$ & $\begin{array}{c}0.046 \pm 0.008 \\
(10) \\
\text { N.S. } \\
0.024 \pm 0.002 \dagger \\
(12)\end{array}$ & $\begin{array}{c}0.030 \pm 0.004 \\
(9) \\
\text { N.S. } \\
0.055 \pm 0.003 \\
\text { (10) } \\
\text { N.S. }\end{array}$ & $\begin{array}{c}0.040 \pm 0 \\
(8) \\
\text { N.S. } \\
\text { N.D. }\end{array}$ & $\begin{array}{c}0-031 \pm 0-003 \\
\text { (8) } \\
\text { N.S. } \\
\text { N.D. }\end{array}$ \\
\hline Isoleucine & $\begin{array}{c}0.032 \pm 0.003 \\
0.070 \pm \frac{(5)}{(7)} 0.003\end{array}$ & $\begin{array}{c}0.027 \pm 0.003 \\
(10) \\
\text { N.S } \\
0.044 \pm 0.004 \\
(12)\end{array}$ & $\begin{array}{c}0.024 \frac{ \pm}{(7)} 0-001^{*} \\
0.046 \frac{ \pm}{(9)} 0.003\end{array}$ & $\begin{array}{c}0.027 \pm 0.001 \\
(7) \\
\text { N.S. } \\
0.051 \pm 0.003 \$ \\
(9)\end{array}$ & $\begin{array}{c}0.031 \pm 0.004 \\
\text { N.S. } \\
0058 \pm 0-003+ \\
\text { (9) }\end{array}$ \\
\hline Leucine & $0.071 \underset{(4)}{ \pm 0.004}$ & $0.030 \pm 0.001$ & $0.036 \pm 0.001$ & $0044 \pm 0.005 \ddagger$ & $0.046 \pm 0.006 t$ \\
\hline Tyrosine & $0.064 \pm 0.005$ & $\begin{array}{c}0.043 \pm 0004+ \\
\text { (Ii) }\end{array}$ & $0.042 \pm 0.002$ & $0033 \pm 0.002$ & $0.048 \pm 0.00 .3+$ \\
\hline Methionine & $0.094 \pm \frac{ \pm 006}{(8)}$ & $\begin{array}{c}0.055 \pm 0.005 \\
(13)\end{array}$ & $\begin{array}{c}0.056 \pm 0.006 \\
(10)\end{array}$ & $\begin{array}{c}0059 \pm 0.007 \S \\
(10)\end{array}$ & $0.056 \pm 0.006 x$ \\
\hline
\end{tabular}

Concentrations of amino acids arc expressed as $\mu \mathrm{mol} / \mathrm{g}$ wet wt.

$(n)=$ Number of experiments. The structures of the compounds are shown in Fig. 1. N.S. = Not significant; N.D. = Not determined.

${ }^{*} 0.05>P>0.025 ;+0.025>P>0.0125:+0.005>P>0.0025 ; 50.0025>P>0.005 ; 00005>P>0$.

Cerebral cortices of control and amino acid injected rats were dissected out 1 and $3 \mathrm{~h}$ after the intraperitoneal administration of the bicyclic amino acid $(4.7 \mathrm{mmol} / \mathrm{kg}$ ) and their weight determined. Homogenization was carried out (10 up and down strokes at (a. $1500 \mathrm{rev} / \mathrm{min})$ in $10^{\circ}$, ice-cold $\mathrm{TCA}(3 \mathrm{ml} / \mathrm{g}$ of wet wt.) and the suspension was centrifuged for $20 \mathrm{~min}$ at $15,000 \mathrm{rev} / \mathrm{min}$. The pellet was resuspended. washed with $5 \mathrm{ml}$ of $10^{\circ}$, TCA and the suspension centrifuged as above. The washing process was repeated once more. TCA wats removed by repeated $(3 \times)$ extraction of the pooled supernatants $(c a .15 \mathrm{ml})$ with an equal volume of diethyl ether. The aqueous phase was tiltered through $0.45 \mu$ pore size Metricel filters and the filtrate lyophilized. The dry residuc was dissolved in $1 \mathrm{ml} \mathrm{of} \mathrm{pH} 2.2$ citrate buffer and $0.5 \mathrm{ml}$ was uscd for a mino acid analysis on a Beckman model $120 \mathrm{C}$ analyser. 


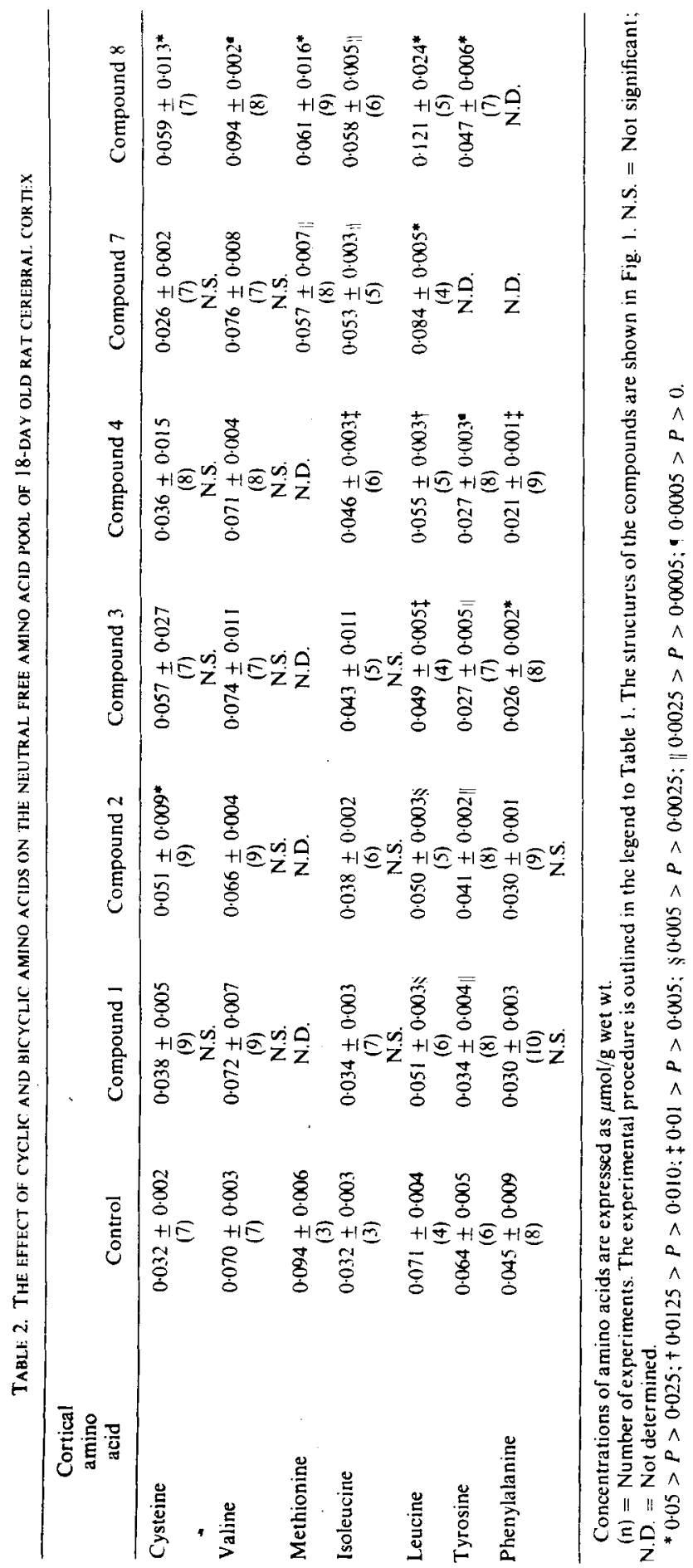


The hydantoin was hydrolysed with barium hydroxide and the amino acid isolated as described above for the other amino acids. Yield: 80 per cent. m.p.: $290-310^{\circ} \mathrm{C} \mathrm{dec}$.

\section{RESULTS}

The effects of the $a$ and $b$ isomers of BCH (compounds 5 and 6. Fig. 1) on the levels of cortical cysteine, valine, leucine, isoleucine, phenylalanine, tyrosine and methionine are summarized in Table 1 . Both isomers caused a marked and protracted decrease of the levels of leucine, tryosine, valine and methionine but no change in the levels of cysteine and isoleucine. The effect of $\mathrm{BCH}-\mathrm{a}$ on phenylalanine could not be determined since under our conditions of analysis the two peaks could not be resolved. The administration of the $\mathrm{BCH}$-b isomer resulted in a significant reduction of the phenylalanine levels at 1 but not at $3 \mathrm{~h}$.

Table 2 presents the changes in the levels of cerebral cysteine, valine, methionine, isoleucine, leucine, tyrosine and phenylalanine $1 \mathrm{~h}$ following the administration of the remaining synthetic amino acids (compounds $1-4,7$ and 8 ) the structural formulae of which are also shown in Fig. 1.

The levels of cysteine were unchanged except for an elevation of about 75 per cent noted after compound 8 was given. Compounds 4,7 and 8 caused an elevation of isoleucine. while valine was elevated only by compound 8 and leucine only by compounds 7 and 8 . The levels of methionine, on the other hand, were depressed by compounds 7 and 8 , while those of tyrosine were depressed by all compounds tested (the effocts of compound 7 not being determined). Although compounds

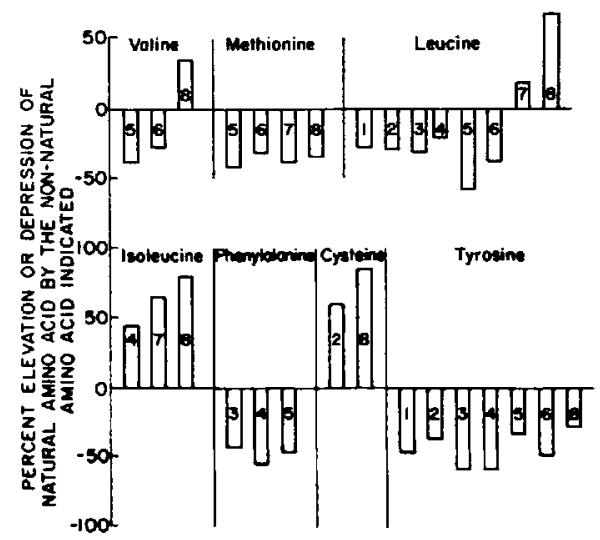

Fig. 2. Histogram representation of the perturbing effect elicited by cyclic and bicyclic amino acids on the neutral amino acids of the rat cerebral amino acid pool. The numbers in the bars refer to the compounds shown in Fig. 1.
I through 4 uniformly reduced the levels of leucine, a 50 per cent reduction of phenylalanine was achieved only following the administration of compounds 3 and 4.

For technical reasons the levels of methionine could not be reliably determined following the administration of compounds 1-4.

For ease of comparison, the per cent of elevation or depression of the cerebral amino acids by the cyclic and bicyclic amino acids is presented in histogram form in Fig. 2.

\section{DISCUSSION}

One of the primary aims of the present study was to see if it was possible to selectively deplete the brain of a specific amino acid without affecting the other amino acids in the pool. It is of interest to note that while our control values are in good agreement with similar data reported by RICHTER \& WAINER (1971) and by BAYER \& MCMURRAY (1967), in most cases they difler appreciably from the values reported by LOWDEN \& LARAMEE (1969). In addition, some of our results parallel observations reported from other laboratories in which natural amino acids were used as the perturbing agent. Thus, the present findings of a differential effect of the cyclic and bicyclic amino acids on the brain pool of leucine and isoleucine are similar to the findings reported by LOWDEN \& LARAMEE (1969), who used phenylalanine as the perturbing amino acid. However, MCKEAN et al. (1968) reported a 55 per cent decrease of cerebral leucine and isoleucine $3 \mathrm{~h}$ after phenylalanine administration to 28 -day-old rats. but only a 10 per cent decrease after the administration of tyrosine. The reasons for the difference between the findings of LOWDEN \& LARAMEE (1969) and MCKEAN et al. (1968) are not clear at this time. However, our observations appear consistent with the findings of the former investigators.

ROBER TS (1968) used leucine as the perturbing amino acid in 42-day-old rats and observed a 3-fold elevation of cerebral leucine concomitant with a moderate reduction of the levels of isoleucine, methionine, valine, tyrosine and phenylalanine. In our study compound 5 exhibited closely similar properties.

Our finding that 1-aminocycloheptane and 1-aminocyclooctane carboxylic acids are both capable of reducing the rat brain pool of phenylalanine by about 50 per cent with a concomitant reduction in leucine and tyrosine levels is of particular interest in the light of the major reductions in cerebral phenylalanine levels ( 80 per cent) reported by RICHTER \& W AINER (1971) after the administration of valine and isoleucine and of the more moderate reduction ( 40 per cent) elicited by the administration of alanine. 
In contrast to phenylalanine. the levels of tyrosine were depressed by all four amino-cycloalkane carboxylic acids suggesting a less stringent control of the efflux from the brain of tyrosine than of phenylalanine. A similar difference in efflux is indicated by the response to compounds $1-4$ of leucine vs isoleucine. Although we noted a statistically significant elevation of isoleucine levels after the administration of 1 -aminocyclooctine carboxylic acid. this was not accompanied by a concomitant change of leucine levels. To our knowledge such a selective elevation of cerebral isoleucine independently of leucine has not been reported. In the bicyclic series, compounds 7 and 8 elicited a similar, though less marked, differentiation in behaviour between leucine and isoleucine. An additional highly specific and hitherto unreported effect was the marked elevation of valine elicited by compound 8 . Finally, the elevation of the levels of cysteine and the corresponding reduction of the levels of methionine by compound 8 is also noteworthy, as it suggests an acceleration of cerebral transsulfuration (VOLPt \& LASTER, 1972).

In contrast to the apparent high specificity exhibited by the bicyclic compounds 7 and 8 . the bicyclic compounds 5 and 6 did not exhibit selectivity. Thus their behaviour is more akin to the behaviour of the natural amino acids described by Richter \& WAINER (1971).

The observed effects of the cyclic and bicyclic amino acids as selective perturbators of the cerebral free amino acid pool provide new avenues of entry for the study of amino acid-dependent dysfunctions of brain (WILTSE \& MENkES, 1972). Foremost among these is the capability they afford to experimentally manipulate cerebral amino acid levels where they are abnormal.

Acknowledgement-We gratefully acknowledge the highly competent assistance of Mr. WAYNE G. OHLSSON.

\section{REFERENCES}

Battistin L. \& Lajtha A. (1970) J. Neurol. Sci. 10, 31.3-322. Bayer S. M. \& MCMUraAy W. C. (1967) J. Neurochem. 14, 695-706.

Buchlerer H. T. \& Lir. V. A. (1934) J. Praki. Chem. 141, $5-43$.

Connors T. A. \& Ross W. C. J. (1960) J. Chem. Soc. $2119-2132$

Christingen H. N., Handlogtin M. E., Lam I. Tager H. S. \& ZAN1) R. (1969) J. hiol. Chem. 244, 1510-1520.

DVONCH W.. FletCher H. \& AlbuRN H. E. (1964) J. ory. Chem. 29, 2764-2766.

HENZe H. R. \& SPEer R. J. (1942) J. Am. chem. Soc. 64, 522523.

Kleinfelter D. C. \& von R. SChleyer P. (1962) Org. Sym. 42, 79-82.

Lowden J. A. \& LaRameE M. A. (1969) Can. J. Bioche'm. 47, 883-888.

MCKian M. C. Boggs D. \& Peterson N. A. (1968) J. Neuroche'm. 15, 235-241.

NeamF K. D. (1969) Prog. Brain Research 29, 185-196.

Piccoli F., Grynbaum A. \& Lajtha A. (1971) J. Neutochem. 18, 1135-1147.

Richier J. J. \& Wainer A. (1971) J. Neurochem. 18, 613 620.

Rober TS S. (1968) Prog. Brain Research 29, 235-243.

Schain R. J. \& Watanare K. S. (1972) J. Neurochem. 19 , 2279-2288.

Slllinger O. Z.. Azcurra J. M.. Ohlsson W. G. Kohl H. H. \& ZaND R. (1972) Fedn. Proc. Fedn. Am. Socs. exp. Biol. 31, 160-165.

Volpe J. J. \& Lasttr L. (1972) Biol. Neonate 20, 385-403. WILTSE H. E. \& MENKES J. H. (1972) in Handhook of Neurochemistry (Lajtha A.. ed.) vol. 7, pp. 143-167. Plenum Press. New York.

Zand R.. Sellinger O.Z. \& Ohlsson W. (1972) Fedn. Proc. Fedn. Am. Socs. exp. Biol. 31, 489.

ZfLinsKY N. \& STADNiKoff G. (1906) Ber. 39, 1722-1732.

Zelinsky N. \& Stadnikoff G. (1911) Z. Physiol. Che'm. 75, 350-351. 